\title{
Cooperation in Local and Global Groups
}

\author{
GERLINDE FELLNER and GABRIELE K. LÜNSER
}

- July 2008 -

\begin{abstract}
Multiple group memberships are the rule rather than the exception. Locally operating groups frequently offer the advantage of providing social recognition and higher marginal benefits to the individual, whereas globally operating groups may be more beneficial from a social perspective. Within a voluntary contribution environment we experimentally investigate the tension that arises when subjects belong to a smaller local and a larger global group. When the global public good is more efficient individuals first attempt to cooperate in the global public good. However, this tendency quickly unravels and cooperation in the local public good builds up.
\end{abstract}

\section{Keywords}

Local public good; Global public good; Cooperation; Social recognition; Social interactions; Experiments

\section{JEL Classification Codes}

C92; D71; D82; H41

\section{Authors}

Gerlinde Fellner

Vienna University of Economics

Augasse 2-6

1090 Vienna

Austria

tel: +43-1-31336-4506

e-mail: gfellner@wu-wien.ac.at
Gabriele K. Lünser

University College London

Dept. of Economics \& ELSE

Gower Street

London WC1E 6BT

United Kingdom

tel: +44-20-7679-5852

e-mail: g.luenser@ucl.ac.uk

Financial support by the University of Bonn and the University of Erfurt is gratefully acknowledged. Lünser is also grateful for additional funding from the Economic and Social Research Council (UK) via ELSE. We thank Dennis Dittrich, Glenn Harrison and Steffen Huck for valuable comments. 


\section{Introduction and Related Literature}

People interacting in groups are often confronted with the problem to allocate their time and efforts between locally operating groups and globally operating groups. Consequently, actions in one group limit the possibility to get involved in the other. By nature, locally operating groups frequently offer the advantage of providing social recognition and higher marginal benefits to the individual, whereas work in global groups may be more beneficial from a broader social perspective, however also more anonymous. This is true for various forms of social situations like group work in organizations, environmental and political engagement or neighborhood interactions.

In the specific context of organizations, the use of teams is one central device to coordinate work activities. It often occurs that employees are assigned to multiple teams on different hierarchical levels and, then, have to allocate their time and efforts between those different team assignments. For example, profit centers are a popular organizational structure. These profit centers are implemented such that some working team members also belong to subteams at a lower hierarchical level to ensure sound communication between different organizational levels.

In academia, research and teaching staff has to divide work time between serving the chair or an institute and working for the department which may require different efforts as administration. Further, as an environmental activist, one faces the decision to operate at a local level, i.e. within neighborhoods and communities, or at a more global level with national and international commitment.

In this paper, we investigate the tension between cooperation for a local public good that offers recognition and facilitates coordination with others and a global public good that is socially more efficient, however more anonymous. Note that another way of thinking about local and global public goods is to differentiate whether the public good is pure or impure in the sense of excludability. In a pure (global) public good others cannot be excluded, while in an impure (local) public good only some subjects can participate (see, for instance, Sandler and Tschirhart, 1980; Cornes and Sandler, 1996).

In the experimental literature on cooperation that largely relies on public good games, it is well established that higher marginal (per capita) returns from cooperation increase the 
willingness to cooperate (e.g., Isaac and Walker, 1988; Isaac et al., 1994; Fisher et al., 1995). When thinking of marginal benefits from local or global group projects, it can be safely assumed that the individual marginal return is higher in the former. Projects or groups that operate on a local level usually provide more direct benefits to their members than global projects. Additionally, interaction is closer, i.e., local groups enable mutual monitoring and hold the opportunity of gaining social approval. Both factors have an advantageous effect on cooperation ${ }^{1}$, especially because they are likely prerequisites of reciprocity and conditional cooperation (e.g., Fehr and Gächter, 2000; Fischbacher et al., 2001). Thus, when people are confronted with the decision to allocate resources to a local or a global project, they are likely to favor the local one.

However, another important behavioral motive in social interaction is the concern for efficiency. Individuals prefer more efficient outcomes over less efficient ones, and tend to choose actions that maximize social surplus or the minimum payoff in a group. This tendency is not only observable for public good provision but also in bargaining or distribution games (e.g., see Engelmann and Strobel, 2004; Levati et al., 2007). Public good projects on a global level usually require the help of many individuals, but once cooperation has emerged, the beneficial effects for society are potentially huge ${ }^{2}$ and often higher than benefits from local projects. Hence, in light of this tension between higher marginal payoffs combined with social recognition in a local group and higher potential revenues for society in a global project, it is interesting to ask what kind of projects are preferred and how individuals choose to divide their efforts among them.

Given a present incentive structure, the tendency to cooperate is not a universal and stable personality trait. A couple of studies have already shed light on whether the composition of groups has an impact on cooperation behavior. For instance, Falk et al. (2003) have shown that people differentiate their cooperative attitude between different groups they are affiliated with. Similarly, Carpenter and Cardenas (2005) uncovered that individuals significantly change their behavior in a common pool resource game depending on the cultural diversity

\footnotetext{
${ }^{1}$ For studies on the effects of monitoring others' behavior on cooperation see, for instance, Sell and Wilson (1991), Cason and Khan (1999) or Carpenter (2007). Social approval as a motive for cooperation and charitable giving has been empirically investigated by Harbaugh (1998), Romano and Yildirim (2001), van de Ven (2002), Gächter et al. (1996), Andreoni and Petrie (2004), Lampel and Bhalla (2007). Models of status seeking within a rational choice framework are presented by Jaeger (2004) or Janssen and Mendys-Kamphorst (2004).

${ }^{2}$ For instance, in line with the current political debate, the endeavor to reduce overall $\mathrm{CO}_{2}$ emissions requires international coordination, but only these global cooperation efforts enable large social benefits worldwide.
} 
within the group. Hence, were it not for diverging incentives, it is likely that individuals still follow different strategies when deciding how to contribute to a local and global project.

In our study, we use a simple public good design where each individual belongs to a smaller local group and a larger global group. In the local group, previous contributions of all members are revealed and the person with the highest contribution in a round is highlighted in the list, which resembles additional social recognition. Contributions in the global group are on the contrary not revealed. To generate the tension between recognition and efficiency, contributions to the global public good entail higher social efficiency despite the fact that the individual marginal benefit from the global public good is lower than from the local public good. Additionally, we have a control group where the efficiency of the local and global public good is equally high. This is achieved by decreasing the marginal benefit of the global public good. Results reveal that stable cooperation is only achieved in the local interaction. When the global public good is more efficient, individuals first attempt to cooperate for the global public good. However, this tendency quickly unravels and cooperation in the local public builds up and remains stable.

A study similar to ours has been conducted by Wachsman (2002), who also investigates individuals' simultaneous contributions to a local and a global public good using additionally different communication rules. The results indicate that individuals always attempt to reach cooperation in the more efficient global exchange. Our results do not confirm these findings, however most likely because of some elementary differences in the design. For instance, Wachsman employed social benefits of full cooperation for the global public good that were by one third higher than in our study. Most importantly, however, our design provides a more anonymous setting where the global group is not easily identifiable to participants. ${ }^{3}$

The remainder of the paper is organized as follows: section 2 gives an overview of the experimental design and procedures. Section 3 presents the results and section 4 concludes with a summary and a brief discussion.

\footnotetext{
${ }^{3}$ We like to mention that Blackwell and McKee (2003) pursued a very similar research question. They find that people cooperate in the more efficient global public good but not at the expense of cooperation in local public goods. Strikingly, the results of this paper rely on only one independent observation per experimental treatment which can hardly be seen as solid evidence. Thus, we abstain from relating our results to these particular findings.
} 


\section{Experimental Design and Procedures}

The main feature of our experimental design puts the same person at the same time into a local environment and into a global environment. Thus, a person simultaneously acts within two environments which are technologically not independent from each other. In reality, multiple memberships are the rule rather than the exception. It seems therefore quite realistic that one's endowment, i.e. the time budget and efforts, has to be divided upon several memberships. In the same line of reasoning actions in one group often limit the possible actions in another group, i.e. actions for the local group restrict the time one can get involved with the global group actions. Our global environment is designed in such a way that it comprises the entire local groups, reflecting for example a situation of different departments in a company or different communities in a state. The implementation of our group design is shown in Figure 1. Eight subjects form a so-called global group $(G)$ which is composed of two local groups $\left(L_{1}\right.$ and $\left.L_{2}\right)$ of four subjects each.

Figure 1: Group composition with two local and one global group

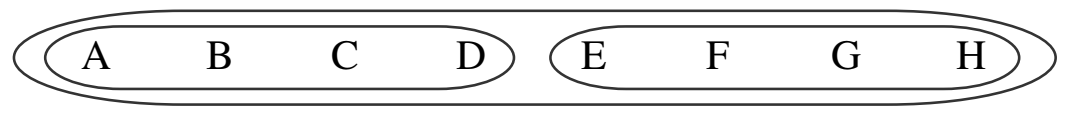

Capital letters represent different subjects in the experiment.

Each subject has to contribute to a slightly altered group cooperation dilemma, also known in its basic form as a linear public good. Many economic decisions happen in an environment where subjects contribute to a group project and the total output is (equally) shared between its members. In our experiment, each subject is endowed with 20 points and has to decide how to allocate this endowment to a local group project, a global group project and a private account respectively. Thus, for example a contribution to the local group project $l_{i}$ diminishes the possible contribution to the global group project $g_{i}$ as well as to the private account, i.e. the following budget constraint has to hold: $l_{i}+g_{i} \leq 20$. For simplicity, the size of the local and the global group project, respectively, are just the sum of all contributions to it. The payoff function for each subject $i$ is the following:

$$
\pi_{i}=20-l_{i}-g_{i}+a_{l} \sum_{j \in L_{m}}^{4} l_{j}+a_{g} \sum_{k \in G}^{8} g_{k}
$$


with $L_{m}=\left\{\begin{array}{c}L_{1} \text { if } i \in\{A, B, C, D\} \\ L_{2} \text { if } i \in\{E, F, G, H\}\end{array}\right.$, where $a_{l}\left(a_{g}\right)$ is the marginal per capita return of the local (global) group project and $j$ and $k$ are the indices for team members of the local and global group respectively.

Our group design allows for an investigation into the influence of efficiency and social recognition in (overlapping) local and global groups. We compare a situation in which the local and the global group projects are equally efficient with a situation in which the global group project is more efficient than the local group project, when at the same time a social recognition mechanism exists only for the local group project in both setups, i.e. subjects can observe each others contributions only in the local project. Therefore, we implemented a history window in which subjects could keep track of contributions to the local group project on an individual level. Moreover, the highest contribution was emphasized, showing clearly who contributed most. Thus, the experimental design includes two treatments. G-low denotes the treatment with a lower global marginal per capita return $a_{g}$ which leads to the same efficiency in the local and global group project and G-high denotes the treatment with a higher global marginal per capita return $a_{g}$ which leads to a higher efficiency in the global group project. Table 1 gives an overview of the experimental design and also shows the parameters for the respective treatments. While the local marginal per capita return $a_{l}$ is set equal to 0.4 in both treatments, resulting in a local efficiency of 1.6, the global marginal per capita return $a_{g}$ differs between both treatments: In $G$-low $a_{g}$ equals 0.2 and in G-high $a_{g}$ equals 0.3 , resulting in a global efficiency of 1.6 and 2.4 respectively. Since the marginal per capita return of the local and global public goods are smaller than 1, a contribution of zero to any group project - is the only strategy that survives repeated elimination of dominated strategies in this finitely repeated game. The socially efficient outcome is achieved when everybody invests nothing to the private account in $G$-low ${ }^{4}$ and fully invests their endowment to the global group project in $G$-high, since this maximizes total payoffs.

The experiment was conducted in the BonnEconLab at the University of Bonn. In total, 128 students of various disciplines who had not taken part in a public goods experiment before, volunteered to participate. Subjects were recruited over the internet with ORSEE (Greiner, 2004). The experiment itself was computerized, using z-Tree (Fischbacher, 2007). It was

\footnotetext{
${ }^{4}$ Note that it does not matter how the endowment is allocated between group projects.
} 
conducted in four sessions with 16 participants in each treatment. Each subject was allowed to participate in one session only.

Table 1: Design of the experiment

\begin{tabular}{lcc}
\hline \hline & \multicolumn{2}{c}{ treatments } \\
& $G$-low & G-high \\
\cline { 2 - 3 } Design & 20 & \\
\# rounds & 64 & 20 \\
\# participants & 4 & 64 \\
local group size & 8 & 4 \\
global group size & 8 & 8 \\
\# global groups & 20 & 8 \\
endowment in points & & 20 \\
Parameters & & \\
$\begin{array}{l}\text { local marginal per capita return } a_{l} \\
\text { (local efficiency) }\end{array}$ & 0.4 & 0.4 \\
$\begin{array}{l}\text { global marginal per capita return } a_{g} \\
\text { (global efficiency) }\end{array}$ & $(1.6)$ & $(1.6)$ \\
\hline \hline
\end{tabular}

Before starting the experiment, instructions were handed out to all participants who were visually separated by booths in the laboratory. ${ }^{5}$ Thereafter, participants had to answer computerized control questions to demonstrate their understanding of the game and the payoff calculation. The experiment did not start before all participants answered all questions correctly. Right before the decision part of the experiment started participants were randomly and anonymously assigned to groups of eight which were additionally divided into two groups of four: The group of eight representing the global group and the group of four representing the local group (see Figure 1). Thus, all subjects of a local group were at the same time - among a second local group - part of a global group. The composition of the local and the global group was kept anonymous and constant during the experiment and subjects were aware of this. We ran four sessions for each treatment comprising two global groups each.

Each of the eight members of a global group received an identification letter, i.e. a capital letter from A through $\mathrm{H}$. In each round, subjects had to allocate their endowment to the

\footnotetext{
${ }^{5}$ Original instructions were written in German. They are available from the authors upon request. A translation is given in the Appendix.
} 
private account and the two respective group projects on the same screen. Thereafter the computer calculated the resulting round payoffs for each subject and gave in addition to the allocation of the own endowment the following feedback: the sum of all contributions and the average contribution of all respective local group members, the sum of all contributions and the average contribution of all respective global group members as well as the round payoff which was furthermore subdivided into the payoff from the local and the payoff from the global group project. Additionally, on the left hand side of the screen subjects could keep track of the individual contributions of the four local group members in all previous rounds. With the help of a history window we displayed past decisions of local group members in columns, each column representing a local group member and each row representing one past period. Each local group member could be identified by his identification code which was displayed above each column. The highest contribution to the local group project in a period was set off in color.

Subjects were not allowed to communicate with each other besides via the experimental software. One session consisted of 20 rounds, i.e. 20 repetitions of the stage game. During the experiment subjects' payoffs were given in points which in the end were exchanged into Euros at a previously known exchange rate of 75 points per 1 Euro. Sessions lasted for about 45 minutes, and on average subjects earned 7.81 Euros.

\section{Experimental Results}

In total, we collected 5120 contribution decisions that are analyzed in this section with respect to our research focus. Table 2 provides a first overview of contributions to the global public good, the local public good and the points kept on the private account, aggregated over the eight independent observations per treatment and averaged over all 20 rounds. At a first glance, the average local contribution is considerably higher than the average global contribution in the G-low treatment, whereas no such difference is observable in the G-high treatment. On average, even more is invested into the global account. The trend over rounds is calculated by the Pearson correlation coefficient between round number and average contributions for each independent observation. It shows that, on aggregate, local as well as global contributions are significantly declining in the G-low treatment. In the G-high treatment, however, local contributions remain fairly constant over rounds while global contributions also decline significantly. 
Table 2: Overview of average results

\begin{tabular}{|c|c|c|c|c|c|c|}
\hline & $\begin{array}{c}\text { average } \\
\text { local } \\
\text { contribution }\end{array}$ & $\begin{array}{c}\text { average } \\
\text { global } \\
\text { contribution }\end{array}$ & $\begin{array}{l}\text { average } \\
\text { private } \\
\text { points }\end{array}$ & $\begin{array}{l}\text { average } \\
\text { earnings }\end{array}$ & $\begin{array}{l}\text { trend over } \\
\text { all rounds } \\
\text { of local } \\
\text { contribution }\end{array}$ & $\begin{array}{l}\text { trend over } \\
\text { all rounds } \\
\text { of global } \\
\text { contribution }\end{array}$ \\
\hline G-low & $\begin{array}{l}10.89 \\
(2.85)\end{array}$ & $\begin{array}{c}1.38 \\
(0.72)\end{array}$ & $\begin{array}{c}7.73 \\
(2.49)\end{array}$ & $\begin{array}{c}7.35 \\
(0.97)\end{array}$ & $-0.4826^{*}$ & $-0.7155^{* *}$ \\
\hline G-high & $\begin{array}{c}4.60 \\
(1.29)\end{array}$ & $\begin{array}{c}5.74 \\
(2.30)\end{array}$ & $\begin{array}{c}9.67 \\
(1.70)\end{array}$ & $\begin{array}{c}8.26 \\
(1.36)\end{array}$ & 0.0019 & $-0.7851^{* *}$ \\
\hline & \multicolumn{6}{|c|}{ treatment differences ( $p$-values) } \\
\hline G-low-G-high & 0.001 & 0.000 & 0.074 & 0.005 & 0.019 & 0.097 \\
\hline
\end{tabular}

Standard deviation is given in parentheses. Average earnings are given in Euros. The trend over rounds is indicated by the average Pearson correlation coefficient. Significance levels of treatment differences result from Mann Whitney U-tests (onetailed).

By using the Binomial test (one-tailed) we state the level of significance at which the null hypothesis can be rejected in favor of the alternative hypothesis that the Pearson correlation coefficient is more often negative than positive:

** $\quad$ significantly more often negative than positive: $\quad \alpha \leq 0.01$

* $\quad$ significantly more often negative than positive: $\quad 0.01 \leq \alpha \leq 0.05$

Figures $2 \mathrm{a}$ and $2 \mathrm{~b}$ display the average local and global contributions over time and reveal different dynamics in both treatments. In the G-low treatment, local contributions exceed global contributions already in round 1 (Wilcoxon-Signed Rank test, $p=0.012$, two-tailed). While local contributions even increase from $45 \%$ of the endowment to about $65 \%$ in first four rounds before they gradually decrease, global contributions quickly drop to nearly zero. In the G-high treatment, however, local contributions fall substantially below global contributions in the first period (Wilcoxon-Signed Rank test, $p=0.017$, two-tailed) and first half of the experiment but seem to remain fairly constant throughout the course of the game, whereas global contributions decline rapidly and fall to below the level of local contributions in the second half of the experiment (neglecting the end-game effect in the last period). 
Figure 2a: Average contribution in G-low

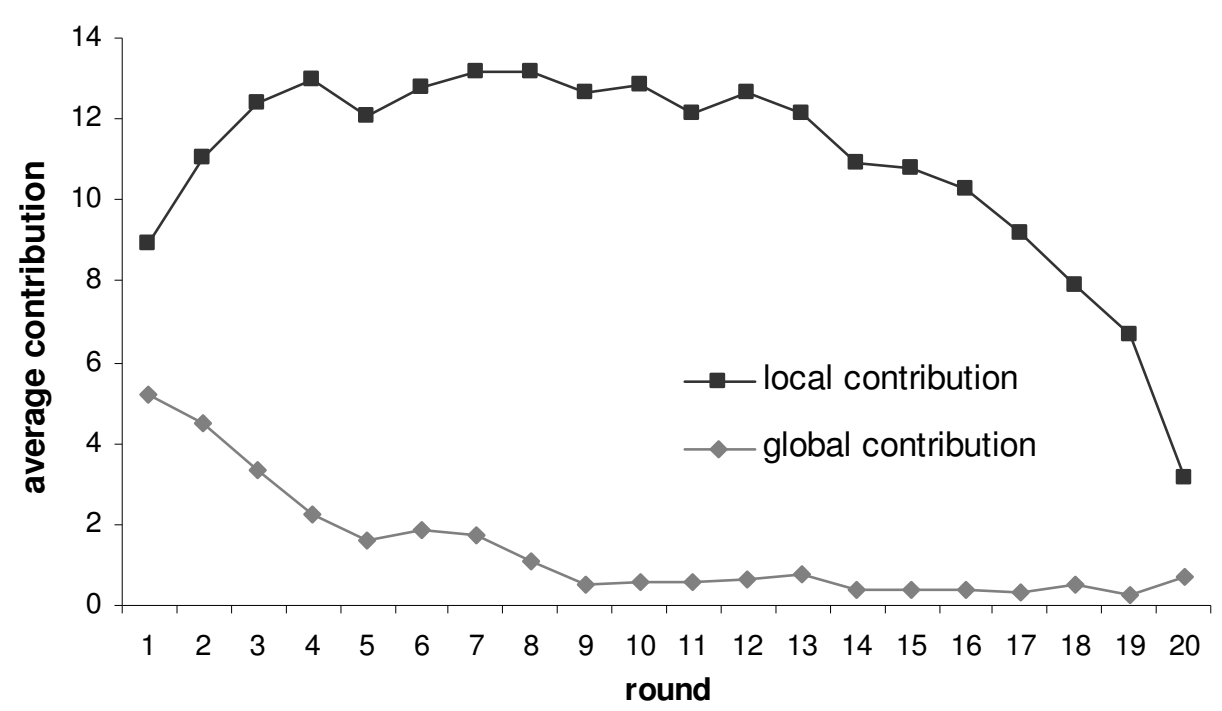

Figure 2b: Average contribution in G-high

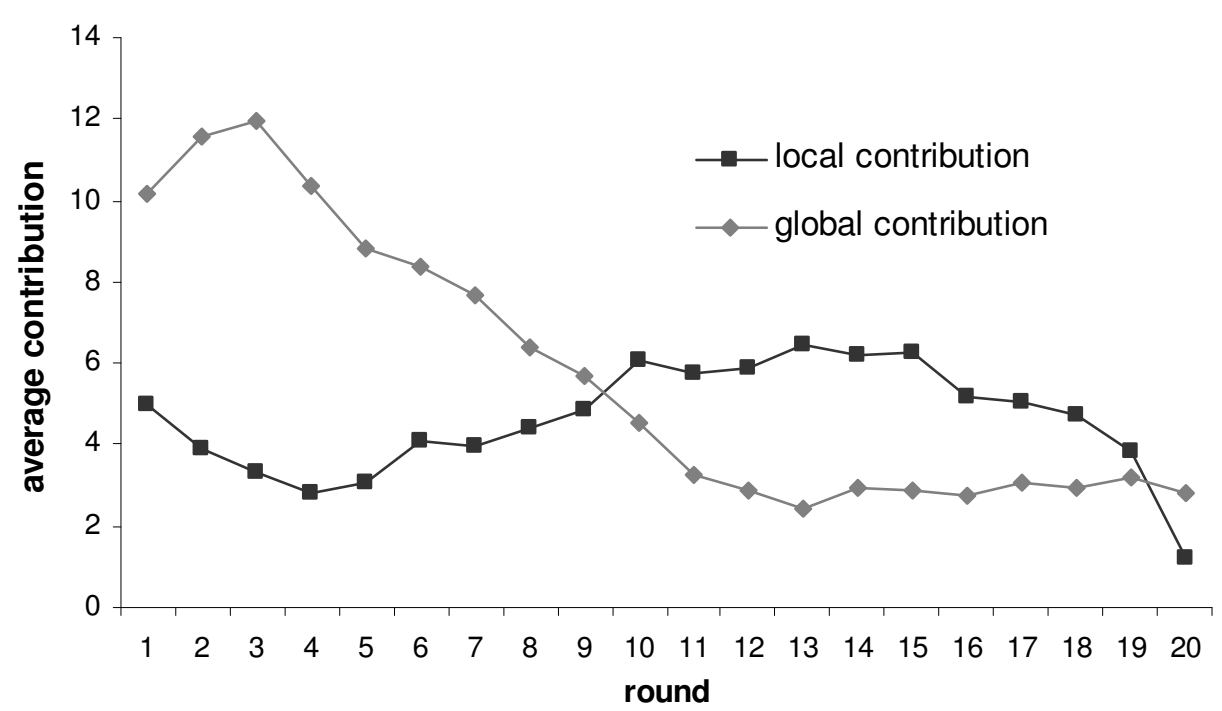

The visual impression of Figures $2 \mathrm{a}$ and $2 \mathrm{~b}$ suggests that in $G$-low, where efficiency is equal for both, the local and the global public good, individuals prefer the local public good. In $G$ high however, the higher efficiency of the global public good attracts higher contributions in the beginning. Still, contributions to the local public good are more stable and do not show the usual decay over time except for the final round. This suggests that after cooperation for the socially more efficient public good cannot be sustained individuals attempt to coordinate their cooperative efforts in the local public good. In the following, this impression is statistically tested in several ways. Before going into detail on the trends of contributions in each treatment, an overview of contributions and efficiency is presented. 
Figure 3: Average total contribution per treatment

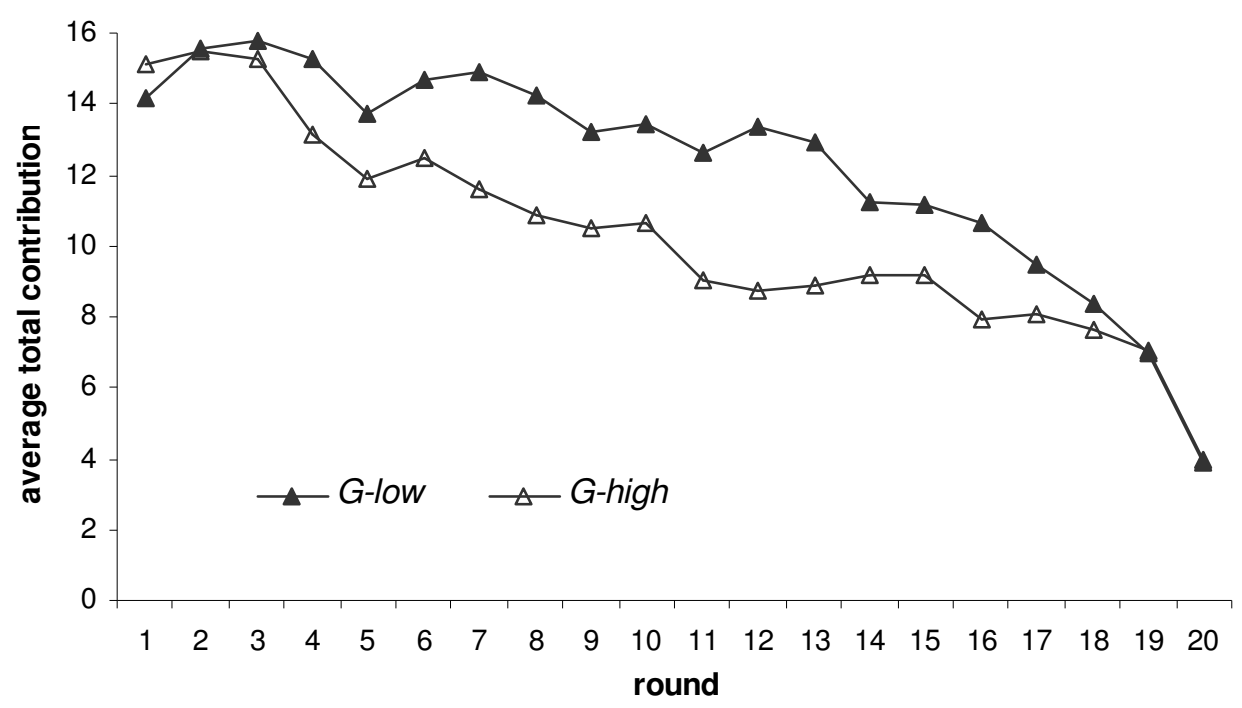

Figure 3 shows average total contributions in the two different treatments. Average total contributions (measured as the sum of global and local contributions) are higher in the G-low treatment. This evidence is substantiated by a Mann Whitney U-test ( $p=0.040$, one-tailed) on average total group contributions. A high initial level of cooperation and early coordination on the local public good are responsible for this somewhat counterintuitive result that in case of potentially higher social benefits cooperation is lower. Average efficiency, measured by the proportion of maximum profit that is actually achieved, lies at $85.51 \%$ in the G-low treatment and only at $64.14 \%$ in the G-high treatment. Thus, although in the G-high treatment cooperation finally stabilizes in the local public good, the coordination difficulties (given the tension between the local and the global public good) have adverse effects on social benefit.

Table 3: Comparison of local and global contributions over time

\begin{tabular}{|c|c|c|c|}
\hline & \multicolumn{3}{|c|}{$\begin{array}{l}\text { Wilcoxon-Signed Ranks test } \\
\text { z-values ( } p \text {-values, two-tailed) }\end{array}$} \\
\hline & \multicolumn{3}{|c|}{$\begin{array}{l}\text { average local contribution vs. } \\
\text { average global contribution in periods }\end{array}$} \\
\hline & $\begin{array}{c}1-20 \\
\text { (overall) }\end{array}$ & $\begin{array}{c}1-10 \\
\text { (first half) }\end{array}$ & $\begin{array}{c}11-20 \\
\text { (second half) }\end{array}$ \\
\hline G-low & $3.52(0.000)$ & $2.52(0.012)$ & $2.52(0.012)$ \\
\hline G-high & $-0.88(0.379)$ & $-2.24(0.025)$ & $1.26(0.208)$ \\
\hline
\end{tabular}

Table 3 shows that in the G-low treatment, local contributions are always significantly higher than global contributions. In the G-high treatment, significant differences can only be found 
in the first part of the experiment, i.e., contributions for the global public good are higher in the first half of the experiment but not in the second. Since these non-parametric comparisons neglect the time series characteristics of the data, a regression analysis is run additionally. We estimate a random effects tobit regression on average group contributions. In particular, we want to investigate the different time trends in local and global contributions in the two treatments.

Table 4: Random effects tobit regression on group contributions

\begin{tabular}{|c|c|c|c|c|c|c|c|c|}
\hline \multirow{3}{*}{ dependent variable } & \multicolumn{4}{|c|}{ G-low } & \multicolumn{4}{|c|}{ G-high } \\
\hline & \multicolumn{2}{|c|}{$l_{i}^{t}$} & \multicolumn{2}{|c|}{$g_{i}^{t}$} & \multicolumn{2}{|c|}{$l_{i}^{t}$} & \multicolumn{2}{|c|}{$g_{i}^{t}$} \\
\hline & coef. & se & coef. & se & coef. & se & coef. & se \\
\hline \multirow[b]{3}{*}{ last round dummy } & $13.111^{* *}$ & 1.011 & $3.941^{* *}$ & 0.453 & $3.726^{* *}$ & 0.576 & $11.516^{* *}$ & 0.862 \\
\hline & $-0.181^{* *}$ & 0.036 & $-0.298^{* *}$ & 0.022 & $0.103^{* *}$ & 0.036 & $-0.567^{* *}$ & 0.039 \\
\hline & $-6.309^{* *}$ & 0.958 & $2.0290^{* *}$ & 0.593 & $-5.354^{* *}$ & 1.026 & $2.248^{*}$ & 1.052 \\
\hline$\sigma_{i}$ & $2.611^{* *}$ & 0.681 & $1.115^{* *}$ & 0.309 & $1.140^{* *}$ & 0.352 & $2.114^{* *}$ & 0.569 \\
\hline$\sigma_{u}$ & $2.445^{* *}$ & 0.140 & $1.286^{* *}$ & 0.086 & $2.455^{* *}$ & 0.144 & $2.611^{* *}$ & 0.153 \\
\hline \# of observations & \multicolumn{2}{|c|}{160} & \multicolumn{2}{|c|}{160} & \multicolumn{2}{|c|}{160} & \multicolumn{2}{|c|}{160} \\
\hline $\begin{array}{r}\text { \# lower censored/ } \\
\text { \# uncensored / } \\
\text { \# upper censored }\end{array}$ & \multicolumn{2}{|c|}{$0 / 160 / 0$} & \multicolumn{2}{|c|}{$43 / 117 / 0$} & \multicolumn{2}{|c|}{$6 / 154 / 0$} & \multicolumn{2}{|c|}{$6 / 154 / 0$} \\
\hline
\end{tabular}

Method: Panel tobit regression $l_{i}^{t}, g_{i}^{t} \in[0,20]$ with global group random effects

$* * p \leq 0.01, * p<0.05$

Table 4 shows that in the G-low treatment, both local contributions $\left(l_{i}^{t}\right)$ and global contributions $\left(g_{i}^{t}\right)$ significantly decrease over rounds. Global contributions in the G-high treatment also decrease significantly over time. However, local contributions in the G-high even increase over rounds as indicated by the positive and significant coefficient. This suggests that in the G-high treatment subjects first indeed attempt to cooperate for the more efficient global public good, yet this tendency weakens quickly. While cooperation for the global public good decreases, subjects cooperate in the local public good and are increasingly able to coordinate contributions on a stable level. Apparently, coordination is easier to achieve in the local group because of closer interaction and signaling possibilities by revealing individual contributions. 
Table 5: Tobit regression on individual contributions including period 1 to 19

\begin{tabular}{|c|c|c|c|c|c|c|c|c|}
\hline \multirow{3}{*}{ dependent variable } & \multicolumn{4}{|c|}{ G-low } & \multicolumn{4}{|c|}{$G$-high } \\
\hline & \multicolumn{2}{|c|}{$l_{i}^{t}$} & \multicolumn{2}{|c|}{$g_{i}^{t}$} & \multicolumn{2}{|c|}{$l_{i}^{t}$} & \multicolumn{2}{|c|}{$g_{i}^{t}$} \\
\hline & coef. & se & coef. & se & coef. & se & coef. & se \\
\hline constant & -2.186 & 1.753 & 0.187 & 2.405 & -5.422 & 3.096 & -1.426 & 4.321 \\
\hline $\begin{array}{l}\text { lagged average } \\
\text { local contribution }\end{array}$ & $1.216^{* *}$ & 0.097 & $-0.247^{* *}$ & 0.087 & $1.414^{* *}$ & 0.204 & $-0.289^{* *}$ & 0.112 \\
\hline $\begin{array}{l}\text { lagged average } \\
\text { global contribution }\end{array}$ & 0.013 & 0.223 & $1.370^{* *}$ & 0.275 & -0.013 & 0.138 & $1.416^{* *}$ & 0.184 \\
\hline $\begin{array}{r}\text { accumulated } \\
\text { frequency of highest } \\
\text { local contribution }\end{array}$ & $2.118^{* *}$ & 0.448 & -0.818 & 0.514 & $1.899^{* *}$ & 0.616 & -0.606 & 0.687 \\
\hline round & $-0.360^{* *}$ & 0.105 & -0.149 & 0.143 & -0.185 & 0.124 & $-0.278^{*}$ & 0.109 \\
\hline $\begin{array}{l}\text { round } * \text { accumulated } \\
\text { frequency of highest } \\
\text { local contribution }\end{array}$ & $-0.090^{* *}$ & 0.022 & 0.030 & 0.018 & -0.074 & 0.040 & 0.048 & 0.039 \\
\hline Wald $\chi^{2}(5)$ & \multicolumn{2}{|c|}{935.84} & \multicolumn{2}{|c|}{142.74} & \multicolumn{2}{|c|}{281.91} & \multicolumn{2}{|c|}{208.82} \\
\hline$p>\chi^{2}$ & \multicolumn{2}{|c|}{$<0.001$} & \multicolumn{2}{|c|}{$<0.001$} & \multicolumn{2}{|c|}{$<0.001$} & \multicolumn{2}{|c|}{$<0.001$} \\
\hline \# of observations & \multicolumn{2}{|c|}{1152} & \multicolumn{2}{|c|}{1152} & \multicolumn{2}{|c|}{1152} & \multicolumn{2}{|c|}{1152} \\
\hline $\begin{array}{r}\text { \# lower censored/ } \\
\text { \# uncensored / } \\
\text { \# upper censored }\end{array}$ & \multicolumn{2}{|c|}{166 / 686 / 300} & \multicolumn{2}{|c|}{835 / 313 / 4} & \multicolumn{2}{|c|}{426 / 634 / 92} & \multicolumn{2}{|c|}{455 / $586 / 111$} \\
\hline
\end{tabular}

Method: Tobit regression $l_{i}^{t}, g_{i}^{t} \in[0,20]$ for periods 1 to 19 with robust standard errors (for clustering of global groups) $* * p \leq 0.01, * p<0.05$

To gain a deeper understanding what drives contributions over time, we investigate individual contributions in a tobit regression model with additional clustering on global groups. (Table $5) .{ }^{6}$ Our analysis only considers data up to period 19 , as we observe a strong endgame effect in the last period. The dependent variables are either local contributions $\left(l_{i}^{t}\right)$ or global contributions $\left(g_{i}^{t}\right)$ and the independent variables are the lagged average contributions of all group members for the local and the global public good, the accumulated frequency of being the group member with the highest local contribution, the round and an interaction variable of frequency of the highest local contribution and round. The rational behind the last variable is 
that one could expect the social signal of being the highest contributor to have a differential effect throughout time.

Results indicate that the lagged average contribution in the local group is influential in both treatments: it positively affects the local contribution and negatively affects the global contribution. The lagged average contribution in the global group positively affects the current global contribution, but has no negative spillover effect on local contributions. The accumulated frequency of being the highest local contributor has a significant positive impact on local contributions, both in the $G$-low and the $G$-high treatment. ${ }^{7}$ However, this effect is weakening over rounds in the G-low treatment and remains constant in the G-high treatment. If the pursuit of social recognition becomes more prominent over time, one would expect a positive interaction between the frequency of highest local contribution previously received and the number of rounds. We find, however, the opposite: the impact of received recognition decreases over time at least in the $G$-low treatment. After controlling for all the other factors, the typical decay is only found for local contributions in the G-low treatment and global contributions in the G-high treatment.

Let us step back and take another look at the different contribution trends over time. In the G-low treatment, global contributions are already on a low level to start with, therefore there is only little room for a distinct declining trend that is observed with local contributions. What is remarkable, however, is that local contributions in the G-high treatment do not show the usual decay. This hints at cooperation patterns in the local public good that are not independent from the global public good. It seems that cooperation first pools on a global level if this promises to be more efficient. However, as soon as this tendency weakens, cooperation is rescued on the local level on which it can be more easily sustained. In contrast, when cooperative efforts concentrate on the local level right from the start as in G-low, no such compensation on another level is possible and cooperation destabilizes.

\section{Concluding Remarks}

The starting point of our study mirrors the basic phenomenon that subjects typically have multiple group memberships. Time or other constraints necessitate that activities are divided

\footnotetext{
${ }^{6}$ The results in Table 5 are qualitatively equivalent to results of a random effects tobit regression. Yet, as in our sample the panel variance decreased with an increase in the number of independent variables we rather report a non-panel tobit model to present more detailed insights.
} 
upon these memberships and, say, leisure. In our design individuals belong to a smaller local group and a larger global group that entirely comprises the local group. Such structures are typically found in work environments, politics, situations with environmental or neighborhood engagement, and even academia.

In large environments, group members are not always able to observe to what extent others are willing to cooperate. In principle, the larger a group the more anonymous are individual actions. In the extreme, local activities are fully traceable while global activities are only observable on an aggregate level as the global group outcome. This paper investigates such a situation where individual peer contributions are observable for the local group interaction but not for the global one. In other words, in our setting only cooperation in the local group is facilitated by social recognition. By varying the marginal benefit in the global group we create two different conditions: one in which the global group is more efficient than the local group and one where both groups are equally efficient. The first condition allows us to study whether cooperation can be sustained in the more efficient global group despite less available information on contributions of peers or, put differently, whether cooperation omits efficiency considerations for the sake of social recognition. The second condition serves as a control for the tension between recognition and efficiency that we study.

We find that when the local and the global group have the same efficiency subjects indeed opt for the local group, where, however, the familiar decay of contributions over rounds occurs. In contrast, when the global group is more efficient individuals first attempt to cooperate there. Yet, this tendency quickly deteriorates and cooperative efforts shift towards the more transparent local group. In the second half of the experiment, we even see higher contribution levels in the (less efficient) local group than in the (more efficient) global group. Overall, contributions in the local group are on a very stable, non-declining level throughout. This suggests that after cooperation for the socially more efficient public good cannot be sustained, individuals attempt to coordinate their cooperative efforts in the local public good where coordination is facilitated by monitoring contributions. Additionally, cooperation in the local public good is associated with social recognition. As we see in a more detailed analysis of behavior over time, the cumulative number of being the highest contributor has a positive impact on the own contributions, even when controlling for the own cooperative disposition.

\footnotetext{
${ }^{7}$ This effect is not a mere effect of cooperative dispositions. When including the lag of the own (local or global) contribution in the regression, the coefficients are still significant.
} 
In summary, our results suggest that while high efficiency indeed attracts contributions initially, cooperation can not be sustained by the prospect of high efficiency gains alone. A smaller, manageable environment where mutual monitoring is possible seems to be more successful in stabilizing cooperation. The large body of literature (relying on various parameterizations) on reciprocal behavior and its potential to stabilize cooperation takes the same line. Future research should therefore address the issue whether the introduction of mutual monitoring and recognition components can persistently promote cooperation for the more efficient (global) public projects, even in large and not readily manageable environments. In light of possible lower social welfare due to coordination problems that arise from the tension between a more transparent local and a more efficient global interaction, the search for appropriate institutions which promote cooperation becomes fundamental. 


\section{References}

Andreoni, James and Petrie, Ragan (2004): Public goods experiments without confidentiality: A glimpse into fund-raising. Journal of Public Economics, 88, 1605-1623.

Blackwell, Calvin and McKee, Michael (2003): Only for my neighborhood? Preferences and voluntary provision of local and global public goods. Journal of Economic Behavior and Organization, 52, 115131.

Cason, Timothy N. and Khan, Feisal U. (1999): A laboratory study of voluntary public goods provision with imperfect monitoring and communication. Journal of Development Economics, 58, 533-552.

Carpenter, Jeffrey P. (2007): Punishing free-riders: How group size affects mutual monitoring and the provision of public goods. Games and Economic Behavior, 60, 31-51.

Carpenter, Jeffrey P. and Cardenas, Juan C. (2007): An inter-cultural examination of cooperation in the commons. Working paper, Department of Economics, Middlebury College.

Cornes, Richard and Sandler, Todd (1996): The theory of externalities, public goods and club goods, $2^{\text {nd }}$ ed., Cambridge University Press, Cambridge.

Engelmann, Dirk and Strobel, Martin (2004): Inequality aversion, efficiency, and maximin preferences in simple distribution experiments. American Economic Review, 94, 857-869.

Falk, Armin; Fischbacher, Urs and Gächter, Simon (2003): Living in two neighborhoods - Social interactions in the lab, Working Paper Series Working Paper No. 150, Institute for Empirical Research in Economics, University of Zurich.

Fehr, Ernst and Gächter, Simon (2000): Fairness and retaliation: The economics of reciprocity. Journal of Economic Perspectives, 14, 159-181.

Fischbacher, Urs (2007): z-Tree: Zurich toolbox for ready-made economic experiments. Experimental Economics, 10, 171-178.

Fischbacher, Urs; Gächter, Simon and Fehr, Ernst (2001): Are people conditionally cooperative? Evidence from a public goods experiment. Economics Letters, 71, 397-404.

Fisher, Joseph; Isaac, R. Mark; Schatzberg, Jeffrey W. and Walker, James M. (1995): Heterogeneous demand for public goods: Behavior in the voluntary contributions mechanism. Public Choice, 85, 249-266.

Gächter, Simon; Fehr, Ernst and Kmend, Christiane (1996): Does social exchange increase voluntary cooperation? Kyklos, 49, 541-554.

Greiner, Ben (2004): The online recruitment system ORSEE 2.0 - A guide for the organization of experiments in economics, Working Paper Series in Economics 10, University of Cologne.

Harbaugh, William T. (1998): The prestige motive for making charitable transfers. American Economic Review, $88,277-282$.

Isaac, R. Mark and Walker, James M. (1988): Group size effects in public good provision: The voluntary contribution mechanism. Quarterly Journal of Economics, 103, 179-200.

Isaac, R. Mark; Walker, James. M. and Williams, Arlington, W. (1994): Group size and the voluntary provision of public goods: Experimental evidence utilizing very large groups. Journal of Public Economics, 54, 136.

Jaeger, William K. (2004): Status seeking and social welfare: Is there virtue in vanity? Social Science Quarterly, $85,361-379$.

Janssen, Maarten C. W. and Mendys-Kamphorst, Ewa (2004): The price of a price: on the crowding out and in of social norms. Journal of Economic Behavior and Organization, 55, 377-395.

Lampel, Joseph and Bhalla, Ajay (2007): The role of status seeking in online communities: Giving the gift of experience. Journal of Computer-Mediated Communication, 12, 434-455. 
Levati, Vittoria; Ploner, Matteo and Traub, Stefan (2007): Are cooperators efficiency- or fair-minded? Evidence from a public goods experiment. Jena Economic Research Papers in Economics 2007-067.

Romano, Richard and Yildirim, Huseyin (2001): Why charities announce donations: A positive perspective. Journal of Public Economics, 81, 423-447.

Sandler, Todd and Tschirhart, John T. (1980): The economic theory of clubs: An evaluative survey. Journal of Economic Literature, 18, 1481-1521.

Sell, Jane and Wilson, Rick (1991): Levels of information and contributions to public goods. Social Forces, 70 , 107-24.

van de Ven, Jeroen (2002): The demand for social approval and status as a motivation to give. Journal of Institutional and Theoretical Economics, 158, 464-482.

Wachsman, Yoav (2002): The effects of group interaction in a public goods experiment with two exchanges. Working Paper 02-5, Department of Economics, University of Hawaii at Manoa. 


\section{Appendix: Instructions (Treatment G-high)}

(Original instructions were in German. They are available from the authors upon request.)

\section{Welcome to the experiment!}

From now on, please do not talk to other participants. If you have a question, please raise your hand and the experimenter will come to your cabin and answer your question privately.

In the experiment you will have to make decisions. These instructions will inform you about the decisions you have to make and their consequences. Depending on your decisions you can earn money which will be paid cash to you at the end of the experiment. Throughout the experiment we will denote all amounts in points. Points will be converted to Euros according to the following exchange rate:

$$
75 \text { points }=1 \text { Euro }
$$

\section{The Experiment}

At the beginning of the experiment the participants will be randomly divided into groups of eight. Within this global group of eight, two local groups of four persons are formed. Therefore, you belong to a local group of 4 persons and at the same time you are a member of a global group of eight persons (see figure). The composition of groups remains constant throughout the experiment. The experiment consists of $\mathbf{2 0}$ rounds. Before the first round, each member of the global group receives an identification code (A, B, C, D, E, F, G or H) on the screen that she keeps for all rounds.

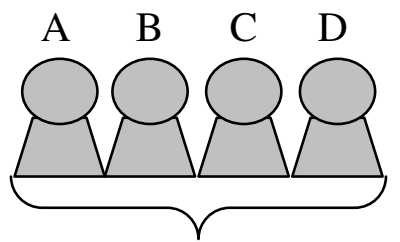

local group 1

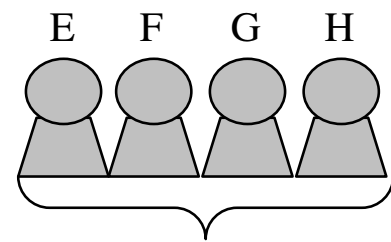

local group 2

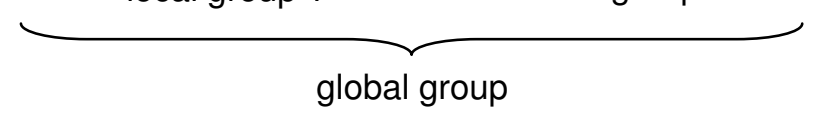

Each round of the experiments consists of two stages. In the first stage you have to decide how to divide your endowment between a private account and two different projects. In the second stage you receive feedback on your income.

\section{Detailed description of each round}

\section{$\underline{\text { Stage 1: }}$}

At the beginning of each round, every participant receives an endowment of 20 points. Your task is to decide, how to use this endowment. In particular, you have to decide how many points to transfer to a private account and how many points to transfer to two different, common projects with your group members. Your total income in each round is the sum of the income from your private account and the income from the two projects.

Your income from the private account 
Each point which you transfer to your private account earns an income of 1 point. That means, if you transfer a specific amount (x points) to your private account, you receive exactly an income of $\mathrm{x}$ points from the private account. No-one except you profits from the points in your private account.

\section{$\underline{\text { Your income from the two possible projects }}$}

There are two possible projects, a local project and a global project.

Your income from the local project is calculated in the following way: The transfers of all four local group members to the local project are summed up and multiplied by 0.4 .

Your income from the local project $=0.4 \times$ (sum of four transfers of the local group)

The income from the local project is calculated in the same way for all local group members, i.e. your local group members receive the same income from the local project as you. Therefore, you and the three other members of your local group benefit from your transfer to the local project.

Your income from the global project is calculated in the following way: The transfers of all eight global group members to the global project are summed up and multiplied by 0.4 .

\section{Your income from the global project $=0.4 \times$ (sum of eight transfers of the global group)}

The income from the global project is calculated in the same way for all global group members, i.e. your global group members receive the same income from the global project as you. Therefore, you and the seven other members of your global group benefit from your transfer to the global project.

Your total income in each round:

\section{Total income $=$}

Income from the private account

$+0.4 \times$ (sum of 4 transfers of the local group to the local project)

$+0.4 \times$ (sum of 8 transfers of the global group to the global project)

For each point you transfer to the private account, you receive an income of 1 point.

Supposing you transferred this point to the local project instead, then the sum of transfers to the local project would rise by one point. Your income from the local project would then rise by $0.4 \mathrm{x} 1=0.4$ points. However, the income of the other local group members would also rise by 0.4 points each, so that the total income from the local project for you and the other local group members (4 persons in total) would rise by 1.6 points. Your transfer to the local project therefore also increases the income of the local group members. Similarly, the transfers of your local group members to the local project increase your income. For each point that your local group members transfer to the local project, you receive an income of $0.4 \times 1=0.4$ points.

For the global project, the case is analogous. Supposing you transferred this point to the global project instead, then the sum of transfers to the global project would rise by one point. Your income from the global project would then rise by 0.4 points. However, the income of the other global group members would also rise by 0.4 points, so that the total income from the global project for you and the other global group members $(8$ persons in total) would rise by 3.2 points. Your transfer to the global project therefore also increases the income of the global group members. Similarly, the transfers of your global group members to the global project 
increase your income. For each point that your global group members transfer to the global project, you receive an income of $0.4 \times 1=0.4$ points.

\section{Stage 2:}

In the second stage you receive feedback on your income and its components in the particular round. On the screen, you see how you have divided your endowment between your private account, the local project and the global project. You learn about your income from the private account, the local project and the global project. Moreover, you see the sum of transfers and the average transfer of the local group to the local project and of the global group to the global project.

Furthermore, on the left side of the screen you will additionally find a list of all transfers of your local group members to the local project. This list is continued throughout all rounds, whereby each local group member is identifiable via his or her unique identification code. The highest transfer within the local group in the particular round is highlighted in green color.

If you have any question, please raise your hand. Before the experiment starts, you are asked to answer some control questions on screen. These questions serve the purpose to check your understanding of the experimental procedure and are not relevant for your final payment. As soon as each participant has answered all control questions correctly, the experiment will start. The sum of all points earned over the 20 rounds will be converted into Euro and paid to you in cash at the end of the experiment.

Thank you for participating and good luck! 